\title{
Travelling to China for the Beijing 2008 Olympic Games
}

\author{
C J Milne, ${ }^{1}$ M T M Shaw ${ }^{2}$
}

${ }^{1}$ Anglesea Clinic, Hamilton, New Zealand; ${ }^{2}$ Worldwise Travellers Health, Hamilton and Auckland Clinics, New Zealand

Correspondence to: Dr C J Milne, Anglesea Clinic, PO Box 228, Hamilton, 3240 New Zealand; chris@ angleseaphysioandsports.co.nz

Accepted 6 March 2008

Published Online First

1 April 2008

\section{ABSTRACT}

The Beijing Olympics will be the world's premier sporting event in 2008. Countries should begin planning for appropriate support for their Olympic athletes.

Experienced medical staff should be appointed early and become familiar with the major medical or injury concerns of athletes and officials. Teams should assemble a comprehensive medical kit. Appropriate medical advice can ensure that athletes will arrive in Beijing in optimal condition. Medical issues particularly relevant to competitors at the Beijing Olympics include heat and humidity, waterborne diseases and air pollution. However, the air pollution probably represents less of a threat than previous media reports would indicate. The Olympic village and venues can be thought of as small enclaves located within a rapidly developing country.

The 26th modern Olympic Summer Games, conducted only once every 4 years since 1896 , will be held in Beijing, China on 8-24 August 2008. There will be approximately 28 major and 302 minor events in 37 venues in Beijing, Hong Kong, Qingdao, Qinhuangdao, Shanghai, Shenyang and Tianjin. The Games in Beijing will play host to the 28 summer sports currently on the Olympic programme. Approximately 10500 athletes are expected to participate in the Games, with around 20000 accredited media bringing the Games to the world and up to several hundred thousand spectators at any one time. ${ }^{1} \mathrm{~A}$ picture of the main stadium, dubbed "the bird's nest", under construction is shown in fig 1.

This paper focuses on relevant health and safety issues for athletes and team staff who will be travelling to the Games. It is based on the best available published evidence from the sports medicine and travel medical literature and the personal experiences of the authors, each of whom has travelled to Beijing in the past 12 months. It needs to be remembered that circumstances can change and that travellers should seek up-to-date travel health advice for China at least 1 month before their departure.

\section{PREPARATORY PHASE}

Although most Olympic teams will develop their own medical plans for their sports men and women, it is important that this includes information on travel health issues. An excellent review for the travelling athlete has been published elsewhere, ${ }^{2}$ although it should be borne in mind that this was specifically written for the 1998 Commonwealth Games in Kuala Lumpur, Malaysia. Areas which need to be covered include personal health issues (including sexual health), a dental assessment, immunisations, advice on insect avoidance and malaria prevention, jet lag, culture shock and acclimatisation. In addition, managing personal stress, personal and team medical kits, female health issues, managing finances and personal security are important issues. Dietary advice for travellers, including travelling athletes, has been discussed elsewhere. ${ }^{3}$

\section{Immunisations}

All those travelling to China for the Games need to ensure that their routine immunisations are up to date. While there are no legally required vaccinations for travel to the country, ${ }^{4}$ all travellers need to be offered vaccination against common foodborne and/or water-borne illnesses such as typhoid and hepatitis A virus, particularly if they are travelling to other less developed countries in the region.

In addition, serious consideration needs to be given to four other vaccines:

- Influenza

- Japanese B encephalitis

- Rabies

- Hepatitis B

Influenza is a disease that remains the most vaccine-preventable on the globe. Athletes, like other travellers, tend to be prone to respiratory tract infection during travel, training and in the Olympic Village. This vaccination would be particularly useful for athletes from countries in the southern hemisphere who have to return to cold wintery conditions.

Vaccination against Japanese B encephalitis should be considered for those going to Shunyi Olympic rowing-canoeing park, an area near to agricultural land and pig farms where mosquitoes remain a concern. Recent advice from the Communicable Diseases Centre (CDC) in Atlanta, USA is that the threat is not sufficient to consider routine vaccination for all rowing and canoe/kayak competitors and officials (E Walkley, personal communication). The experience of one author (CM) at the World Rowing Junior Championships held at the Shunyi course would tend to bear this out.

The third vaccine to be considered, particularly in the Beijing region, is rabies. This disease was the leading cause of death due to infectious diseases in China from May 2006 to March 2007. Whether the vaccine is used or not, all travellers should be advised about what they are to do if bitten by any suspect mammal. This is covered below.

Finally, athletes in particular contact sports such as boxing may be required to have vaccination against hepatitis B virus. 


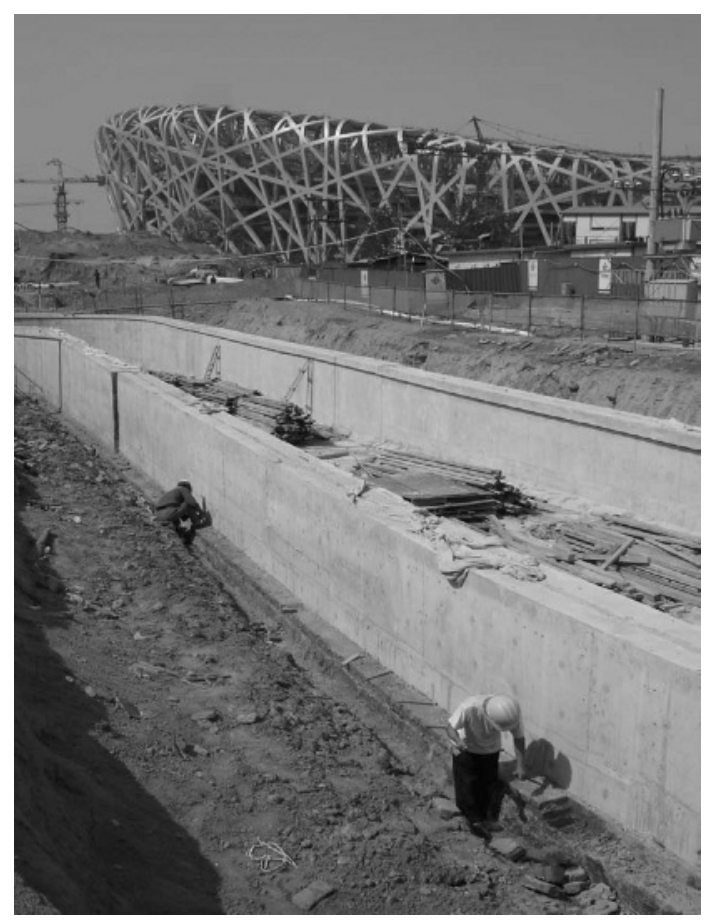

Figure 1 National stadium ("bird's nest"), Olympic Green, Beijing: venue for track and field events, football and the opening and closing ceremonies.

\section{Other important seasonal and specific disease information for travellers}

There are a number of diseases specific to the region of which travellers need to be aware. ${ }^{5}$ Although the risk for them may be low, precautions and preventive measures are advised at all times.

\section{AIDS/HIV}

China's overall burden of HIV and AIDS is low. ${ }^{6}$ An estimated 650000 people in China (less than $0.05 \%$ of the total population) were living with HIV at the end of 2005. Heterosexual transmission is overtaking injection drug use as the dominant mode of HIV transmission.

\section{Avian flu}

Since December 2003 there have been instances of "avian flu" among poultry in south-east Asia. While it is unusual for humans to get influenza virus infections directly from poultry or birds, there have been 25 human cases of the disease with 16 deaths. ${ }^{7}$ Travellers are thus advised to avoid places such as poultry farms and bird markets where live poultry are raised or kept, and to avoid contact with sick or dead poultry.

\section{Cholera}

Immunisation is not internationally required by the World Health Organization. The risk to travellers attending venues of the Olympic Games is negligible and therefore the vaccine is not routinely recommended.

\section{Dengue fever}

Dengue occurs as frequent, often widespread, outbreaks. The incidence is highest in south-eastern China. There is an increased risk in coastal urban areas below 1500 metres elevation. Most disease transmission occurs during the summer months. Prevention of dengue fever consists of taking protective measures against mosquito bites.

\section{Food and water}

Outside the Games venues, awareness of water-borne and foodborne problems is advisable. It is our recommendation that all drinking water should be considered a potential health risk and sterilisation is advisable. Bottled water will be available at all venues and at stores throughout China. All meat, poultry and seafood must be well cooked and served while hot. Vegetables should be well cooked and served hot. Salads and mayonnaise are best avoided. The experience among three teams at the World Rowing Junior Championships in August 2007 in Shunyi was favourable. Among three teams of rowers totalling over 100 athletes who ate at the designated hotel and venue exclusively, there were only two cases of gastrointestinal upset in a 2 -week period (C J Milne, unpublished data).

\section{Influenza}

Influenza is highly seasonal and in Beijing the epidemic season ranges from October to March. The flu vaccine is advised for travellers aged $>50$ years, those with chronic disease or a weakened immune system and those competitors who wish to have it.

\section{Japanese encephalitis}

The risk of Japanese encephalitis is greatest in rural pig-breeding agricultural areas of the central and eastern provinces, especially during the warm rainy months from May to September. There is a low risk of transmission in urban areas due to the relative absence of mosquitoes, but the area of Shunyi is an at-risk region for the disease and vaccination against Japanese encephalitis has been recommended for travellers who will be attending the water sports in the region. ${ }^{8}$ However, recent CDC advice is that routine immunisation for travellers to the Shunyi venue may not be required (E Walkley, personal communication).

\section{Leishmaniasis}

Visceral leishmaniasis (kala azar) occurs in the temperate central and north-eastern provinces. Most cases have bee reported from Gansu Province; cutaneous leishmaniasis has been reported from the Xinjiang autonomous region. All travellers to these areas should avoid being bitten by sand flies.

\section{Malaria}

The risk of malaria for travellers to the sports venues during the Olympic Games will be negligible. ${ }^{4}$ For those travelling to other regions of the country, malaria occurs in Hainan, Yunnan, Anhui, Henan, Hubei and Jiangsu. There is no malaria risk in urban areas, in the densely populated plain areas or at altitudes above 1500 metres. ${ }^{49}$ If travellers are planning side trips to risky areas, they need to be advised to adhere to appropriate malaria chemoprophylaxis and careful personal protective measures. ${ }^{10}$

\section{Rabies}

The incidence of rabies in China is second in the world after India. In 2006 there were 3200 cases of rabies were reported, with 140000 people in Beijing having sustained animal bites. From May 2006 through to March 2007, rabies was the number one cause of death due to infectious diseases. ${ }^{8}$ All animal bites or scratches, especially from a dog, should be taken seriously and immediate medical attention sought. Access to rabies vaccine or 
rabies immune globulin may require emergency evacuation to another country. Rabies is rare among tourists.

\section{Sudden acute respiratory syndrome (SARS)}

The sudden acute respiratory syndrome (SARS) is not currently considered to be a risk for travellers to the country.

\section{Schistosomiasis}

There is a risk of schistosomiasis throughout the year in southern tropical areas and from June through August in temperate areas. Major endemic areas include the Yangtze River Valley, including tributaries and adjacent lakes. In 2003 alone, 843000 Chinese were infected, most of them living in frequently flooded areas along the Yangtze River where the carrier snail has an ideal habitat, according to reports. ${ }^{5}$ All travellers should avoid swimming, wading or bathing in freshwater lakes, ponds or streams.

\section{Travellers' diarrhoea}

All travellers are advised to ensure strict food and water hygiene. Tap water is not recommended, even in the resort hotel regions. Bottled water, which is readily available, should be used. If travellers' diarrhoea occurs, a high intake of nonalcoholic fluids such as sports drinks should be maintained and dairy produce avoided. Diarrhoea not responding to treatment with an antibiotic or chronic diarrhoea may be due to a parasitic disease such as giardiasis, amoebiasis or cryptosporidiosis.

\section{TRAVEL PHASE}

\section{Jet lag and sleep pattern}

Jet lag occurs when there is desynchrony between normal daily rhythms and the local environment. As the natural daily rhythm is about $25 \mathrm{~h}$, travel in an easterly direction tends to produce greater jet lag as it compresses a $24 \mathrm{~h}$ day. Medical publications on travel offer varying advice on the use of medication to minimise the effects of time zone change. Yung et $a^{11}$ recommend that melatonin $3-5 \mathrm{mg}$ should be taken at

\section{Box 1 General travel guidelines}

- Plan to travel to the venue at least 1 week before competition begins.

- Take books, magazines and your own preferred music in your carry-on bag.

- Be aware that recently introduced regulations severely limit the ability of travellers to take extra fluids on international flights. Generally, these must be purchased air-side at the airport from which you depart.

- Exercise during the flight. Stretch in your seat and get up and walk down the aisle of the aircraft every few hours.

- Adjust your watch to the time of your destination during the flight at a time when you are devoid of environmental cues.

- Eye shields, ear plugs or relaxing music played over the aircraft or one's own personal sound system are all useful adjuncts to promoting sleep.

- Try to arrive at the destination during daylight hours as natural light can help in resetting the "body clock" to local Beijing time.

- If there is sufficient time after accreditation has been completed, try to complete an easy training session. bedtime (local time) starting the first evening after arrival and continuing for the next 5 days. In contrast, the World Health Organization does not recommend melatonin but suggests that short-acting sedatives may be used. ${ }^{12}$ These are used routinely by members of teams competing in the Super 14 international rugby competition. ${ }^{13}$ Arguably, this annual competition involves travel over the most time zones of any in world sport. Elite athletes can perform with distinction, even after roundthe-world travel. ${ }^{14}$

\section{Venous thromboembolism}

Previous experience with teams travelling long distances to the Sydney Olympics in 2000 has shown an incidence of deep vein thrombosis (DVT) of about 1\% (R Budgett, personal communication). Findings of the recent WRIGHT epidemiological studies indicate that the risk of venous thromboembolism (VTE) approximately doubles after a long-haul flight ( $>4 \mathrm{~h}$ ) and also with other forms of travel where travellers are exposed to prolonged seated immobility. The risk increases with the duration of the travel and with multiple flights within a short period. ${ }^{15}$ Other risk factors identified were obesity, extremes of height, use of oral contraceptives and the presence of prothrombotic blood abnormalities. Nevertheless, the absolute risk of VTE per $>4 \mathrm{~h}$ flight in a cohort of healthy individuals was relatively low (1 in 6000). For those people at high risk of DVT, a preventive strategy therefore needs to be in place well in advance of travel to China. We advise use of pressure stockings plus low molecular weight heparin in selected cases.

General guidelines for travel to and from the venue are listed in box 1.

\section{VILLAGE PHASE}

\section{Arrival}

Team members arriving in Beijing after long flights can be expected to be tired and fractious. However, all team personnel must first go through the process of accreditation. Although this process has been progressively streamlined, there may still be a delay of several hours before they arrive at the Olympic Village. To smooth the accreditation process it is imperative that all athletes and officials accurately complete documentation for their National Olympic Committee (NOC) in good time for it to be forwarded to the Beijing Organising Committee for the Olympic Games (BOCOG).

Beijing International Airport is approximately $20 \mathrm{~km}$ from the Olympic Village. Team members can expect the trip to take up to $2 \mathrm{~h}$, especially at peak times. Beijing, like other Olympic host cities, will be making strenuous attempts to facilitate travel for members of the Olympic Family, but delays are inevitable in a city of 15 million people.

On arrival at the Olympic Village it is suggested that all teams adjust to local time as quickly as possible. Avoid the temptation to sleep during the day as this will delay the establishment of a normal sleep/wake cycle at the Village and prolong any symptoms of jet lag.

\section{The Olympic Village experience}

For any athlete, particularly the first-time Olympian, living in the Olympic Village can be an intimidating prospect. An excellent analysis by Miller was published in "Gold Minds". ${ }^{16}$ Steve Scott, American middle distance runner said: "The pressure at the Games is constant - day after day. It's like a tourniquet. The closer it got, the harder it was to relax." Surviving - and indeed maximising - the Village experience is of 
vital importance if one is to compete well. Teams should make an effort to make their quarters a small part of "home" as this is appreciated by athletes and helps to build team unity.

\section{Food}

Athletes and officials can be assured that the food on offer at the Olympic Village will be of high quality and, as far as is practicable, tailored to their specific dietary preferences. Different cultural needs (eg, Halal cooking) will be generally well catered for and exacting hygiene standards ensure that the incidence of food-borne illness is low. ${ }^{3}$ The major challenge is to avoid eating too much-the so-called "dining hall syndrome". Athletes need to adopt a disciplined approach to eating to avoid gaining weight. Food intake should be timed to allow for absorption well before training and competition. The dining hall is open $24 \mathrm{~h}$ a day so there is ample opportunity to replenish glycogen stores even after a late evening competition. Athletes with significant food allergies (eg, peanuts, gluten) should inform the doctor performing their pre-Games assessment of these particular issues.

\section{Sleeping}

Teams at the Beijing Olympics will be accommodated in newly built tower blocks adjacent to the main Games venue. Athletes from different countries will be housed in close proximity to one another, so Village residents will need to show consideration for their compatriots. In particular, those who have already finished their competition need to be reminded about partying late into the night in the Olympic Village. Earplugs are therefore well worth packing.

\section{Transport}

Transport can be a major problem at the Olympic Games because many of the venues are some distance away. In Beijing most venues will be within a 60 min bus ride from the Olympic Village. Nevertheless, traffic jams occur so it is suggested that teams leave for any venue $90-120 \mathrm{~min}$ before the time they are expected there.

\section{Security}

Over the past 25 years there has been an escalating emphasis on security at the Olympic Games. This has intensified since the events of 11 September 2001 when hijacked aircraft were able to crash into and destroy the Twin Towers in New York City. Security at the Olympic Village and all venues will be at a high level and athletes must learn to get on with their daily routines in spite of this security. The accreditation pass must be taken everywhere; at an Olympic Games it is more important than your passport.

\section{Safety}

Do not neglect basic safety procedures. Traffic accidents are a particular concern: the country had 380000 traffic accidents in 2006 with 90000 road traffic deaths. ${ }^{8}$ In China vehicles drive on the right hand (European/American) side of the road. Competitors from the UK, Australasia, Japan, Southern Africa and the other few countries that drive on the left therefore need to be particularly careful with road safety.

Sexual health is a particular concern. Athletes need to be aware that the incidence of sexually transmitted disease is rising, and even elite sports competitors can be HIV positive. Condoms, which will be freely available at the polyclinic at the Olympic Village, should therefore be used and high-risk sexual encounters avoided.

\section{AT THE VENUE \\ Heat, humidity and dehydration}

The average daytime temperature in Beijing in August will be about $28^{\circ} \mathrm{C}$. There will be about $75 \%$ humidity and air pollution and rain storms are to be expected. At those venues in cities further south (eg, Hong Kong, Shanghai) the temperature may be significantly warmer. Average daytime temperatures in Hong Kong, for example, are likely to reach $30-32{ }^{\circ} \mathrm{C}$ with a high relative humidity of $80 \%$. By night there will be only partial relief as the temperature drops to around $22^{\circ} \mathrm{C}$.

Advice regarding optimal hydration strategies has undergone a profound sea change in the past decade. Hitherto, athletes were advised to drink to a predetermined schedule of 400$1200 \mathrm{ml}$ per hour of exercise. However, a spate of cases of

Table 1 Weather forecasts at the Shunyi venue during the 2007 World Rowing Junior Championships

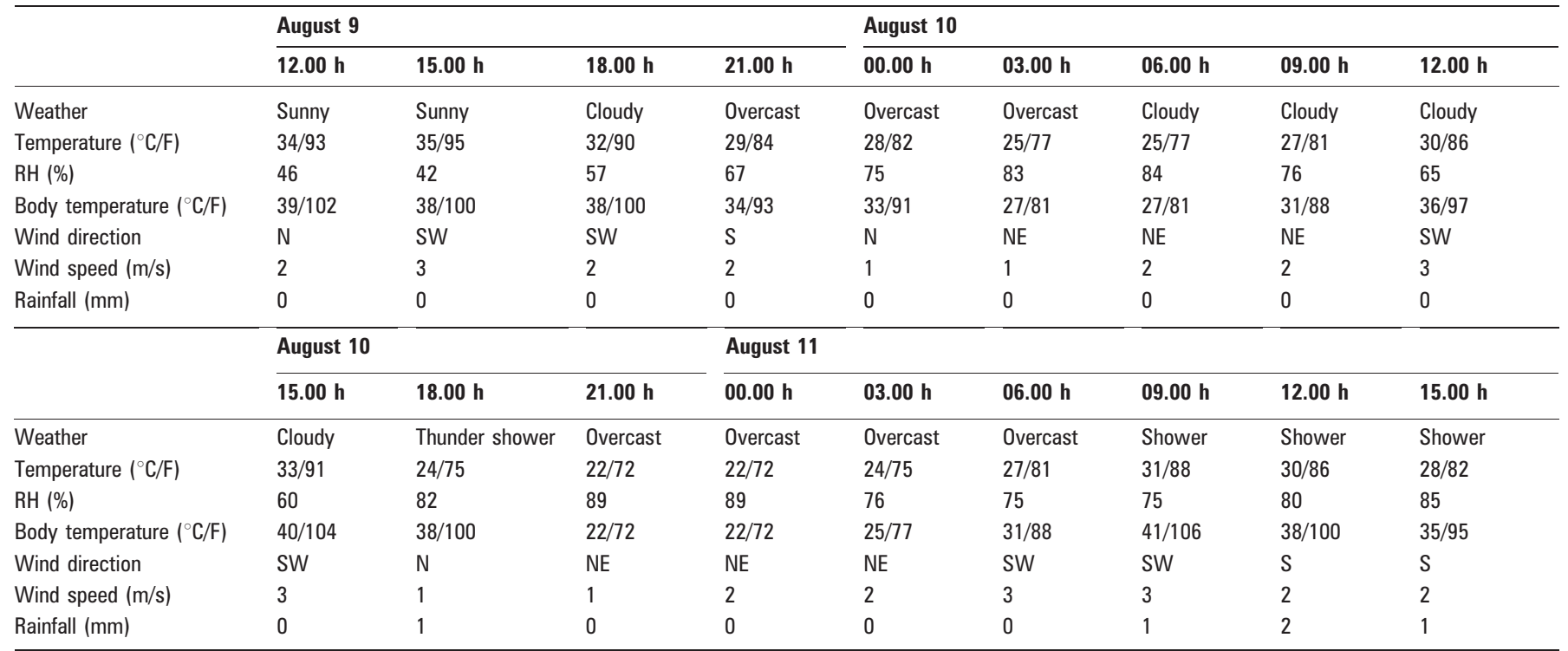

$\mathrm{RH}$, relative humidity. 


\section{Box 2 Summary of recommendations}

\section{(A) Preparatory phase}

- Personal health issues: remember dental check-up

- Immunisations:

- Routine: update these

- Influenza: for at-risk individuals

- Rabies: possible role

- Typhoid: possible role

- Hepatitis A: if travelling to less developed areas

- Hepatitis B: contact sports (eg, boxing, wrestling)

- Specific disease information:

- AIDS/HIV: increasing heterosexual transmission

- Avian flu: avoid bird markets and poultry farms

- Cholera: negligible risk

- Dengue fever: avoid mosquito bites in daytime

- Gastroenteritis: avoid risky food, eat at the Village

- Influenza: elderly, unwell at greater risk of complications

- Japanese encephalitis: theoretical risk at Shunyi venue but immunisation not universally required

- Leishmaniasis: avoid sandfly bites

- Malaria: no risk in urban areas

- Rabies: seek immediate medical attention after any animal bite

- SARS: not a current risk

- Schistosomiasis: mainly in Yangtze River Valley

\section{(B) Travel phase}

- Jet lag: short-acting sedatives \pm melatonin

- Venous thromboembolism: variable risk, preventive strategy

(C) Village phase

- Arrival: get accredited, establish normal sleep-wake cycle

- Olympic Village experience: provide some reminders of home country

- Food: avoid overeating

- Sleeping: show consideration for fellow residents

- Transport: expect delays and allow for them

- Security: don't let it oppress you

- Safety: care with crossing the road

\section{(D) At the venue}

- Heat and humidity: drink according to thirst, daily weigh-in

- Pollution: less of a concern than previous media reports indicate

- Acclimatisation: arrive early in Beijing

- Food: may need a packed lunch at the venue

(E) After the event

- Written reports and debriefing session

hyponatraemia in endurance events has prompted a radical rethink in recent years. The best available evidence ${ }^{17}{ }^{18}$ suggests that athletes should start the day well hydrated and drink according to thirst as each day progresses. A set of scales back at the Village can ensure that athletes know their "wet weight". Athletes need to take their own bottles of sports drink along to training and competition venues and ensure that these are not tampered with. At the venue they should stay out of the sun before competition to minimise insensible fluid loss. Cooling jackets worn before the event can also ensure that athletes reach the start line in optimal condition.

\section{What is known about this topic}

- The Olympic Games is the world's premier sporting festival and medical support of athletes has become increasingly sophisticated.

- Competitions staged in hot environments pose an additional challenge for athletes.

- This is the first summer Olympic Games to be held in Asia since the Seoul Olympics in 1988.

\section{What this study adds}

- Specific knowledge of the environment in Beijing and other major Chinese cities can be of assistance to athletes preparing for the 2008 Beijing Olympic Games.

- Recent experience with teams competing at the World Rowing Junior Championships indicates that heat and humidity are likely to represent significant challenges, but that air pollution should be less of a problem than previous media reports have indicated.

\section{Pollution}

Significant air pollution has been reported from a variety of sites in China. Athletes with respiratory disorders such as asthma are likely to be more significantly affected by air pollution and need to take this into account when planning their training. At the 2007 World Rowing Junior Championships held at the Olympic rowing and canoeing venue at Shunyi, significant air pollution was evident on most competition days. Visibility was reduced to 1000 metres and low flying aircraft on their final approach to nearby Beijing Airport were often barely visible. However, the firing of rockets cleared the air in the immediate vicinity within hours. Spirometric tests performed on elite New Zealand rowers competing at the World Rowing Junior Championships in August 2007 showed no fall in forced expiratory volume in $1 \mathrm{~s}$ or vital capacity from baseline data obtained in New Zealand 2 months before travel (J C Milne, unpublished data). Paradoxically, on days when the pollution had been dispersed-for example, on Finals day of the Championshipsthe air temperature in the sun rose to $36^{\circ} \mathrm{C}$ with $41 \%$ humidity (J C Milne, unpublished data).

The Chinese authorities are making strenuous attempts to minimise air pollution around the time of the 2008 Olympic Games. Two of the proposed measures include temporary closure of factories near to major competition venues and some form of "cloud seeding" to cause rain and help clear the lower atmosphere.

\section{Acclimatisation}

For most athletes arriving from most northern hemisphere countries, Beijing will also be in late summer during the time of the Olympic Games so there is no major environmental challenge. By contrast, athletes arriving from the extreme north of Europe or America or temperate countries in the southern hemisphere will need to invoke an acclimatisation strategy. Usually this involves exercising in the heat, possibly at some intermediate location en route to Beijing. Ordinarily, a 1to 2 -week period of progressively increasing exercise intensity is sufficient to improve heat tolerance. Beijing is at an altitude of 
only 60 metres so separate acclimatisation for this is not required. Weather forecasts at the Shunyi venue during the 2007 World Rowing Junior Championships are shown in table 1 and give an indication of the range of conditions that could be expected in August 2008.

\section{Food}

In most cases the pre-competition meal can be consumed at the Olympic Village before departure for the competition venue. In some cases (eg, yachting, rowing) prolonged travel times may necessitate taking packed food to the venue. In most circumstances this can be arranged in conjunction with the BOCOG provided sufficient notice is given. Management for the affected teams should clarify this issue before arrival at the Olympic Village. Athletes with special dietary needs (eg, those with diabetes) need to plan their competition nutrition meticulously in conjunction with a dietician, develop a system that works well in the preceding months and stick to it. ${ }^{19}$

\section{AFTER THE EVENT}

On return from Beijing there should be a formal debriefing session. Before the session all section managers should prepare a written report. From the medical team, significant medical issues should be highlighted. The written reports provide a basis for discussion at the debriefing session and sentinel events should be examined in detail. Any lessons learned can then be passed onto the NOC and enable a continuous improvement in the services to athletes.

A summary of these recommendations is shown in box 2 .

\section{CONCLUSION}

In the lead-up to the Olympic Games, athletes devote many of their waking hours to optimal preparation for their event. Team support staff need to be equally well prepared. The injured or unwell athlete should find the medical room to be an open welcoming place, and receive prompt appropriate treatment.

As we wrote in our conclusion to the paper published in the lead-up to the Sydney 2000 Olympic Games: "Early access to well qualified, experienced sports medicine experts is something that elite athletes have come to expect. At the Olympic Games, they deserve nothing less." 20

\section{Competing interests: None.}

The authors do not necessarily represent the views of the Beijing Olympic Games Organizing Committee or of any other agency connected with the Beijing Olympic Games of 2008.

\section{REFERENCES}

1. Anon. Official site of the Beijing 2008 Olympic Games. http://en.beijing2008.cn/ (accessed 6 July 2007).

2. Young $\mathbf{M}$, Fricker $P$, Maughan $R$, et al. The traveling athlete: issues relating to the Commonwealth Games, Malaysia, 1998. Br J Sports Med 1998;32:77-81.

3. Leggat PA, Nowak M. Dietary advice for airline travel. J Travel Med 1997;4:14-6.

4. World Health Organization. International travel and health: China. www.who.int/ ith/countries/chn/en/ (accessed 9 July 2007).

5. Anon. Worldwise country travel health reports. www.worldwise.co.nz/members/ country-reports.asp \#Asia (accessed 10 July 2007).

6. World Health Organization. HIVIAIDS situation in China. www.wpro.who.int/china/ sites/hsi/overview.htm (accessed 10 July 2007).

7. Anon. Cumulative number of confirmed human cases of avian influenza A/(H5N1). Reported to the World Health Organization. www.who.int/csr/disease/ avian_influenza/country/cases_table_2007_06_29/en/index. html laccessed 10 July 2007).

8. MacDonald S. Beijing 2008 Olympics: preparations for medical emergencies. Victoria, Canada: GeoSentinel Annual Site Directors Meeting, 2007.

9. International Association for Medical Assistance to Travellers. World malaria risk chart. http://www.iamat.org/pdf/WorldMalariaRisk.pdf (accessed 15 July 2007)

10. Shaw M, Leggat PA. Travelling to Australia for the Sydney 2000 Olympic and Paralympic Games. J Travel Med 2000;7:200-4.

11. Yung A, Ruff T, Torres T, et al. Manual of travel medicine. 2nd ed. Melbourne: IP Communications; 2004:229-32.

12. World Health Organization. International travel and health. Geneva: WHO, 2007 http://whqlibdoc.who.int/publications/2005/9241580364_chap2.pdf (accessed 6 July 2007).

13. Cook J, Harcourt P, Milne C. Providing team care. In: Brukner P, Khan K, eds. Clinical sports medicine. 3rd ed. Sydney: McGraw-Hill, 2007.

14. Milne C, Fuard MH. Beating jet lag. Br J Sports Med 2007;41:401.

15. World Health Organization. WHO research into global hazards of travel (WRIGHT) project 2007. www.who.int/cardiovascular diseases/wright project/phase1 report/ en/index.html (accessed 9 July 2007).

16. Miller B. Gold minds. Ramsbury: The Crowood Press, 1997.

17. Hew-Butler TD, Verbalis JG, Noakes TD. Updated fluid recommendation: position statement from the International Marathon Medical Directors' Association (IMMDA) Clin J Sport Med 2006;16:283-92.

18. Noakes TD. Hydration in the marathon. Sports Med 2007;37:463-6.

19. Burke L, Deakin V. Clinical sports nutrition. 2nd ed. Sydney: McGraw-Hill, 2000.

20. Milne C, Shaw M, Steinweg J. Medical issues relating to the Sydney Olympic Games. Sports Med 1999;28:287-98. 